\title{
Magnetic Mesoporous Photonic Cellulose Films
}

Michael Giese, Lina K. Blusch, Maik Schlesinger, Georg R. Meseck, Wadood Y. Hamad, Mohammad Arjmand, Uttandaraman Sundararaj* and Mark J. MacLachlan*

E-mail: mmaclach@chem.ubc.ca, u.sundararaj@ucalgary.ca

\section{Content}

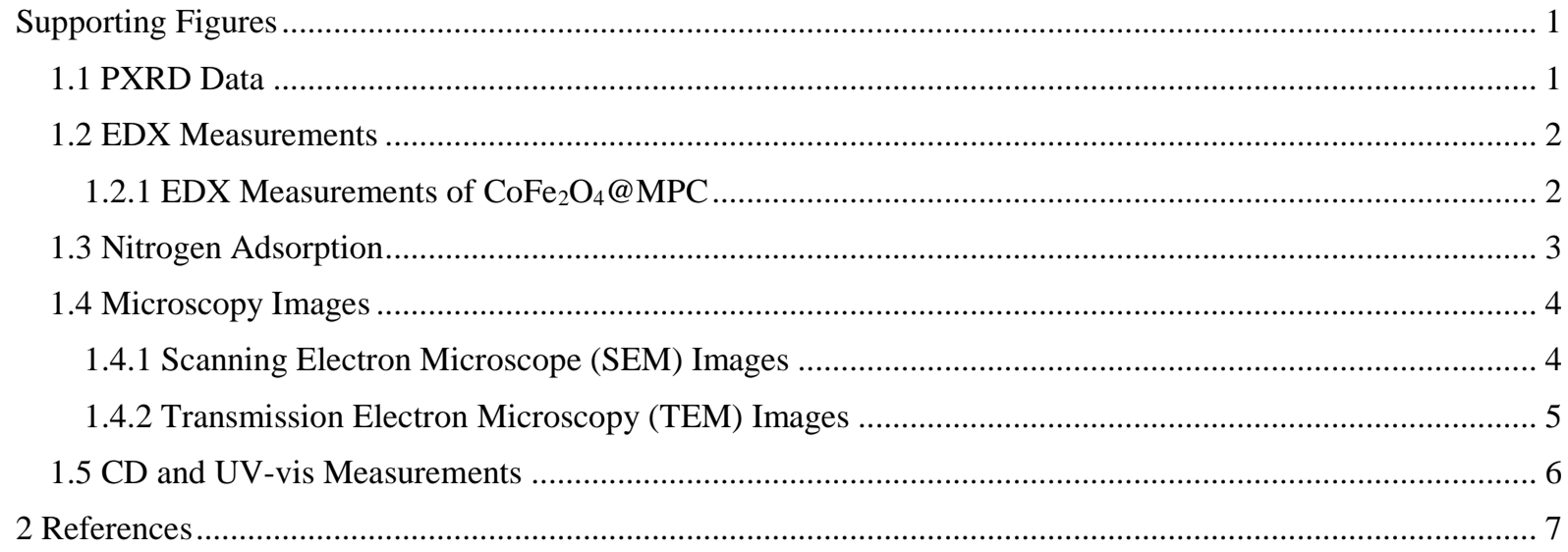




\section{Supporting Figures}

\subsection{PXRD Data}
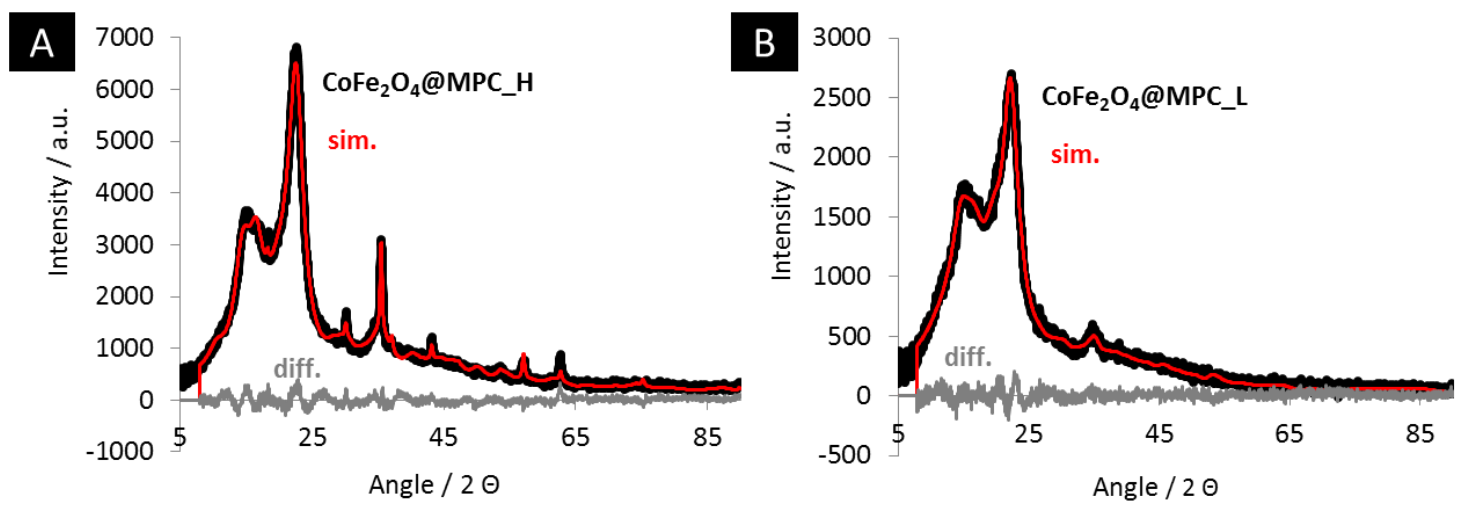

Figure S1. Powder X-ray diffraction patterns (black lines) of (a) $\mathrm{CoFe}_{2} \mathrm{O}_{4} @ \mathbf{M P C} \_\mathbf{H}$ and (b) $\mathrm{CoFe}_{2} \mathrm{O}_{4} @$ MPC_L. The refinement (red lines) was done using the Ruland-Rietveld analytical approach of the crystal structures of cellulose $\mathrm{I} \alpha$ (CCDC 792796) and the appropriate metal oxide $\left(\mathrm{CoFe}_{2} \mathrm{O}_{4}\right.$ : COD ID 5910063). The difference between the measurement and the refinement is indicated in grey. The overall degree of crystallinity was determined to be $~ 83 \%\left(\mathrm{CoFe}_{2} \mathrm{O}_{4} @ \mathbf{M P C} \_\mathbf{H}\right)$ and $~ 50 \%\left(\mathrm{CoFe}_{2} \mathrm{O}_{4} @ \mathbf{M P C} \_\mathbf{L}\right)$. 


\subsection{EDX Measurements}

1.2.1 EDX Measurements of $\mathrm{CoFe}_{2} \mathrm{O}_{4} @ \mathrm{MPC}$
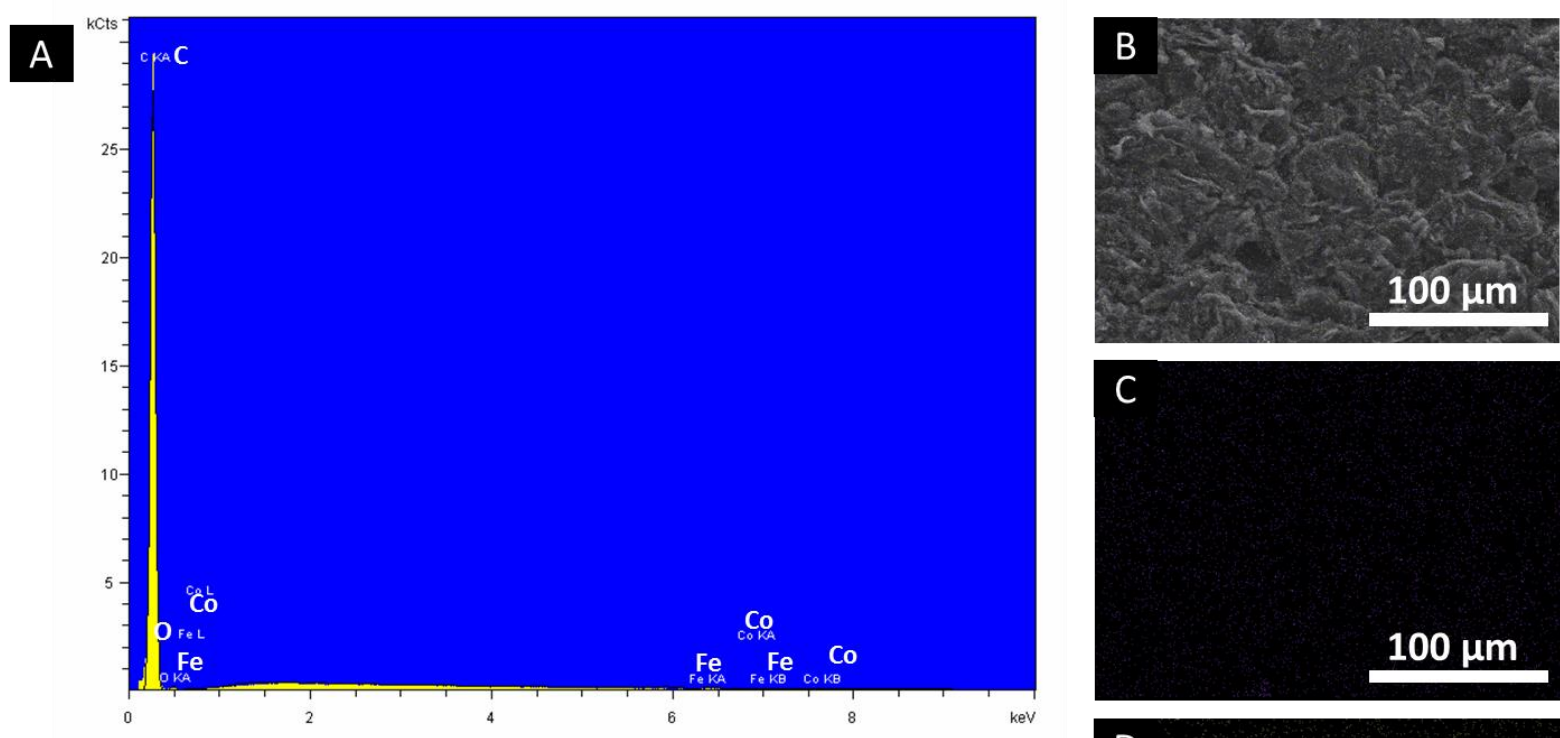

D

$100 \mu \mathrm{m}$

Figure S2. EDX spectra (A), EDX mapping combined with SEM image (B) and EDX mapping for $\mathrm{Fe}(\mathrm{C})$ and $\mathrm{Co}(\mathrm{D})$ of $\mathrm{CoFe}_{2} \mathrm{O}_{4} @ \mathbf{M P C} \_\mathbf{L}$.

\section{A}
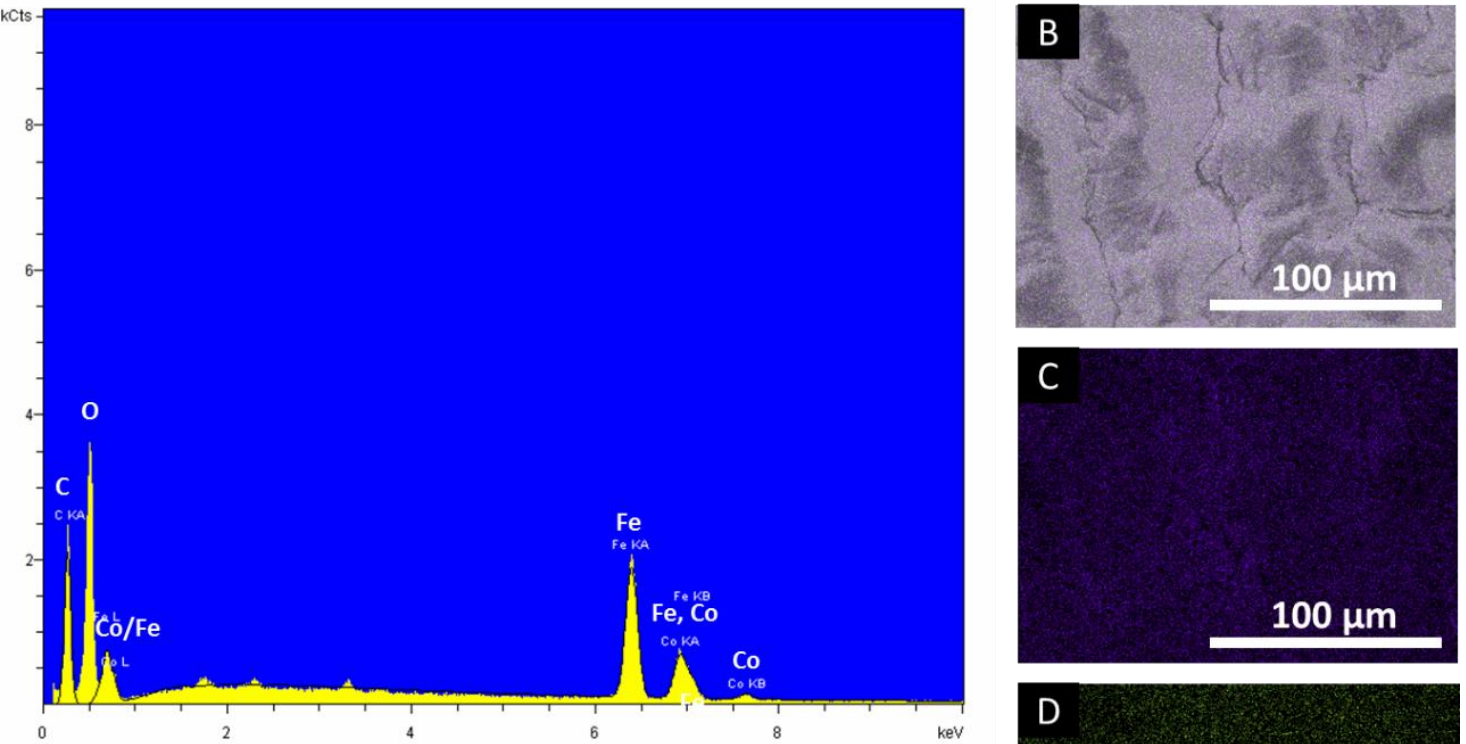

D

$100 \mu \mathrm{m}$

Figure S3. EDX spectra (A), EDX mapping combined with SEM image (B) and EDX mapping for $\mathrm{Fe}(\mathrm{C})$ and $\mathrm{Co}(\mathrm{D})$ of $\mathrm{CoFe}_{2} \mathrm{O}_{4} @ \mathrm{MPC} \_\mathbf{H}$. 


\subsection{Nitrogen Adsorption}
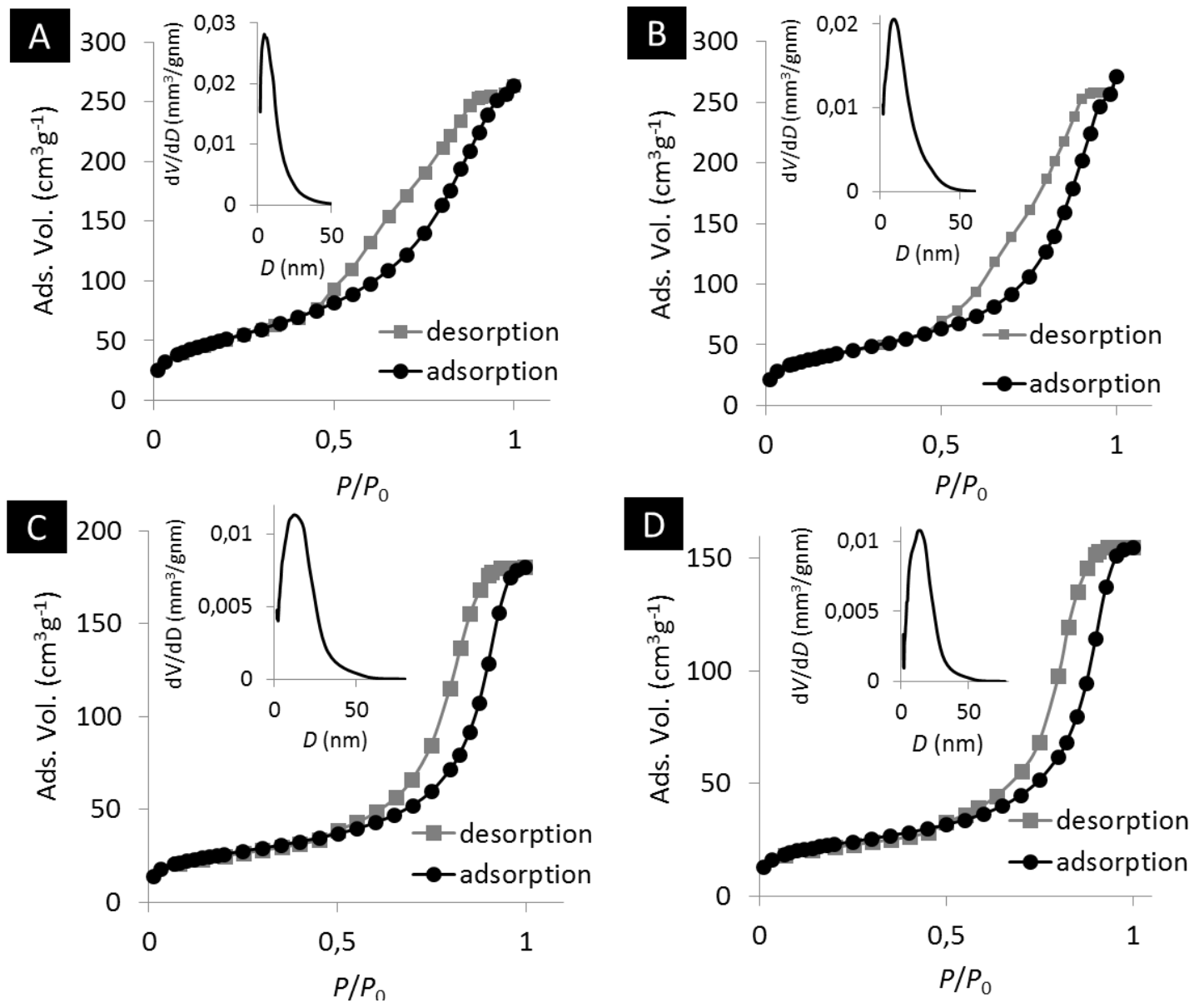

Figure S4. Brunauer-Emmett-Teller nitrogen absorption curves and the calculated BarrettJoyner-Halenda (BJH) pore-size distributions as an inset. A) pure MPC with a surface area of $188 \mathrm{~m}^{2} \mathrm{~g}^{-1}$ and a pore size of $7 \mathrm{~nm}$, B) MPC treated under the same basic conditions applied for the NP synthesis with a surface area of $152 \mathrm{~m}^{2} / \mathrm{g}$ and a pore size of $9.9 \mathrm{~nm}, \mathrm{C}$ ) $\mathrm{CoFe}_{2} \mathrm{O}_{4} @$ MPC_L with a surface area of $91.0 \mathrm{~m}^{2} / \mathrm{g}$ and a pore size of $11.4 \mathrm{~nm}$ and D) $\mathrm{CoFe}_{2} \mathrm{O}_{4} @$ MPC_H with a surface area of $78.66 \mathrm{~m}^{2} / \mathrm{g}$ and pore size of $12.1 \mathrm{~nm}$. 


\subsection{Microscopy Images}

1.4.1 Scanning Electron Microscope (SEM) Images
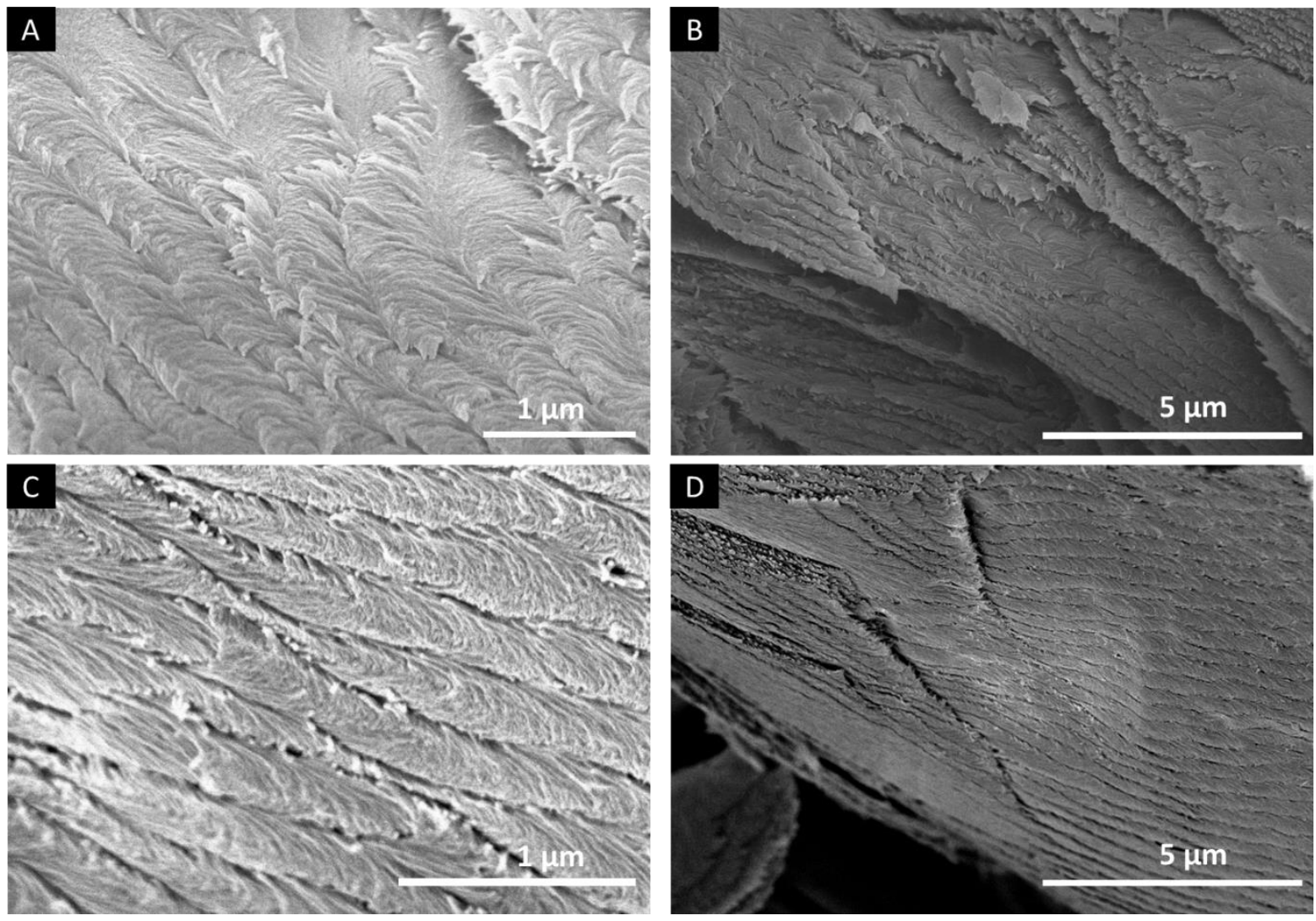

Figure S5. SEM images of $\mathrm{CoFe}_{2} \mathrm{O}_{4} @ M P C \_H\left(A\right.$ and B) and $\mathrm{CoFe}_{2} \mathrm{O}_{4} @ M P C \_L$ (C and D) as representative examples visualizing the intact chiral nematic organization. 
1.4.2 Transmission Electron Microscopy (TEM) Images
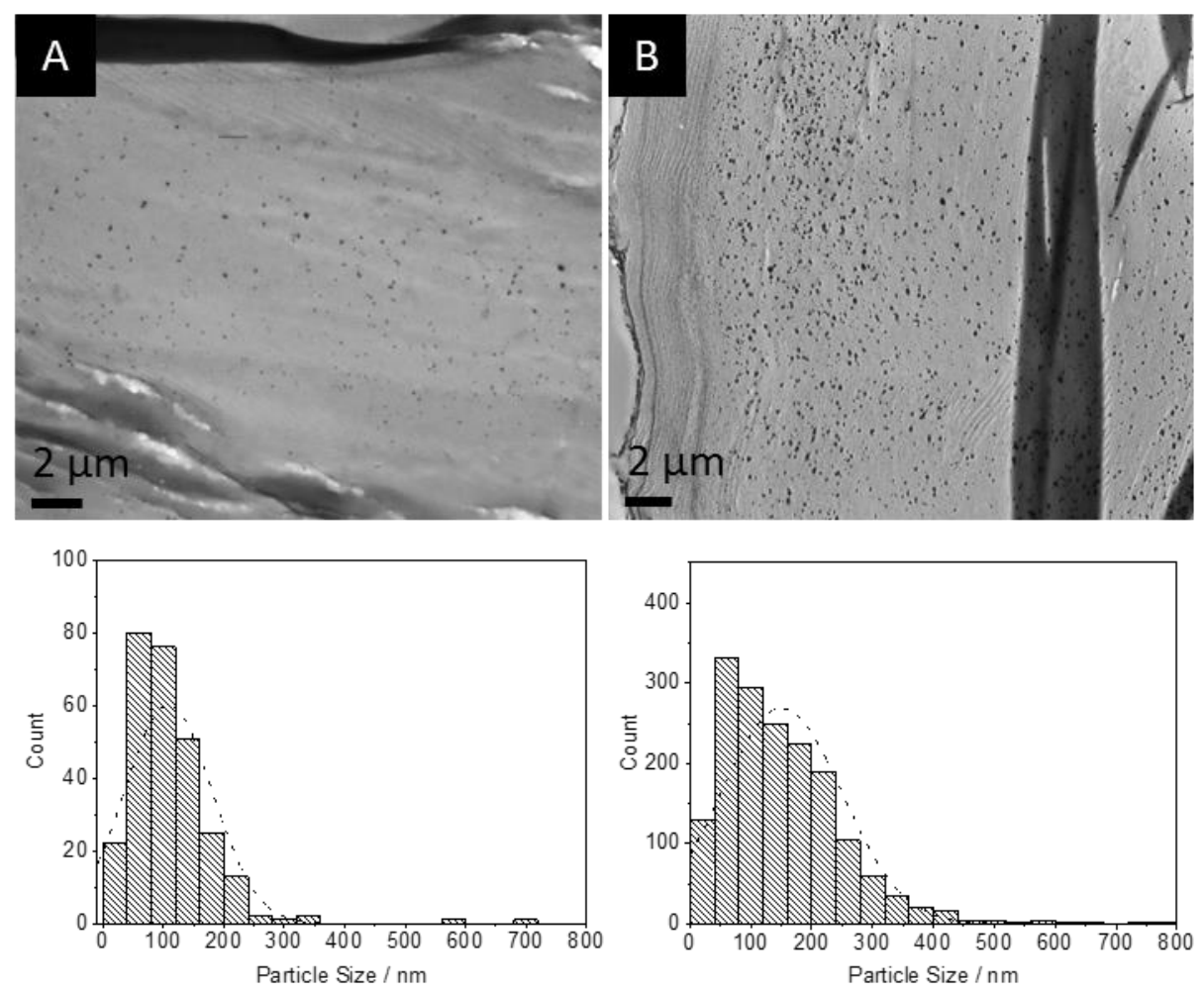

Figure S6. TEM images and particle size distribution of $\mathrm{CoFe}_{2} \mathrm{O}_{4} @ M P C \_L$ (A) and $\mathrm{CoFe}_{2} \mathrm{O}_{4} @$ MPC_H (B) show well dispersed particles that appear to follow the layered structure. 


\subsection{CD and UV-vis Measurements}
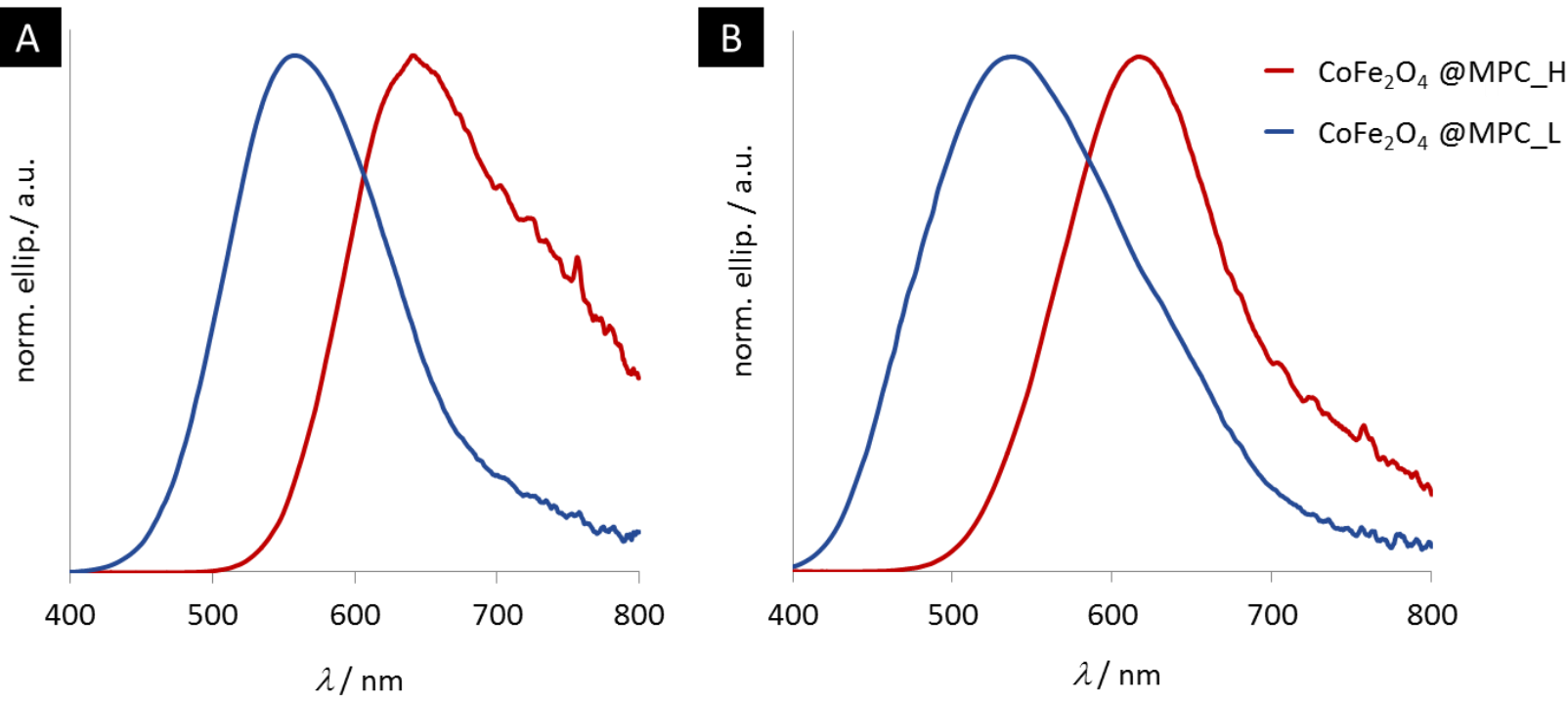

Figure S7. CD spectrum of $\mathrm{CoFe}_{2} \mathrm{O}_{4} @$ MPC (low and high) after soaking overnight in $\mathrm{H}_{2} \mathrm{O}$ (left) and $\mathrm{EtOH}$ (right). (Spectra of films soaked overnight in $\mathrm{EtOH}$ are depicted in the main manuscript.)
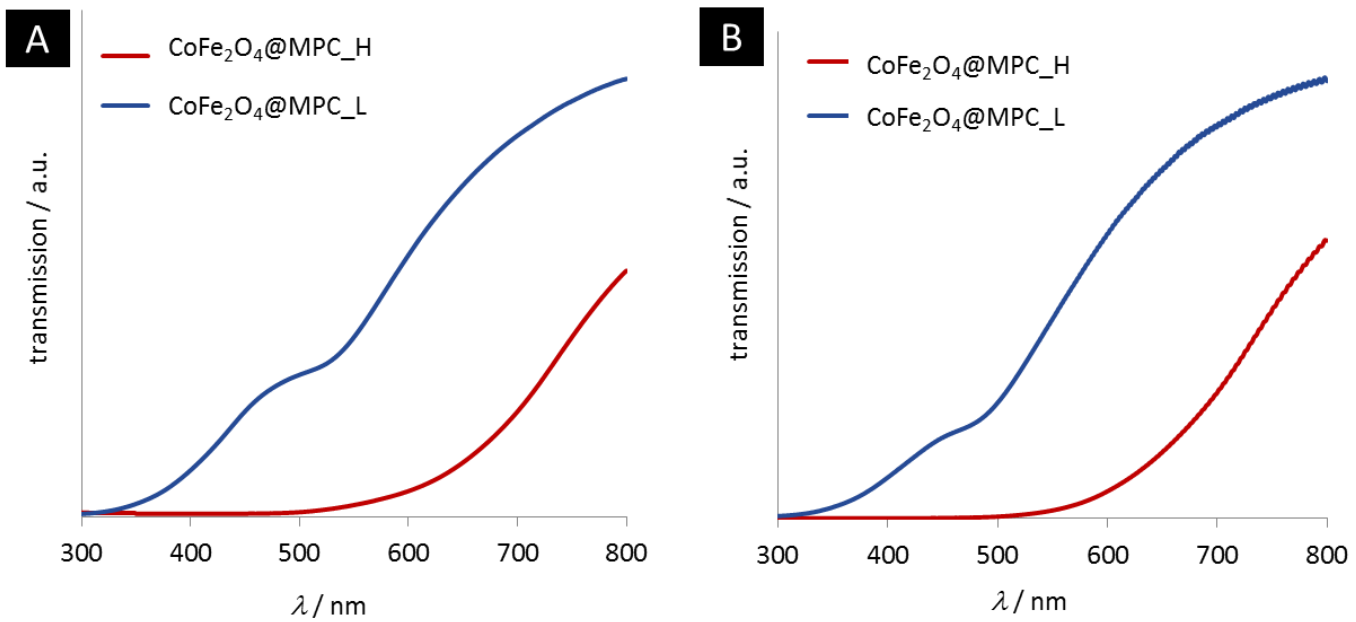

Figure S8. UV-vis spectra of $\mathrm{CoFe}_{2} \mathrm{O}_{4} @$ MPC (low and high) after soaked overnight in a) $\mathrm{H}_{2} \mathrm{O}$ and b) $\mathrm{EtOH}$.

Table S1. Comparison of NP size, BET surface area and CD data for $\mathrm{CoFe}_{2} \mathrm{O}_{4} @ M P C$ films.

\begin{tabular}{|c|c|c|c|c|}
\hline & $\begin{array}{l}\mathrm{NP} \\
\operatorname{size}^{[\mathrm{a}]} \\
{[\mathrm{nm}]}\end{array}$ & $\begin{array}{l}\text { BET } \\
\text { Surface } \\
\text { area } \\
{\left[\mathrm{m}^{2} / \mathrm{g}\right]}\end{array}$ & $\begin{array}{l}\text { CD } \\
\text { abs. }^{[\mathrm{b}]} \\
{[\mathrm{nm}]}\end{array}$ & $\begin{array}{l}M_{\mathrm{S}} \\
{[\mathrm{emu} / \mathrm{g}]}\end{array}$ \\
\hline $\mathrm{CoFe}_{2} \mathrm{O}_{4} @ \mathrm{MPC} \_\mathrm{H}$ & 150 & 79 & 630 & 3.9 \\
\hline $\mathrm{CoFe}_{2} \mathrm{O}_{4} @ \mathrm{MPC} \_\mathrm{L}$ & 108 & 91 & 540 & 0.2 \\
\hline
\end{tabular}

[a] Average NP size determined from TEM [b] Measured in EtOH. 

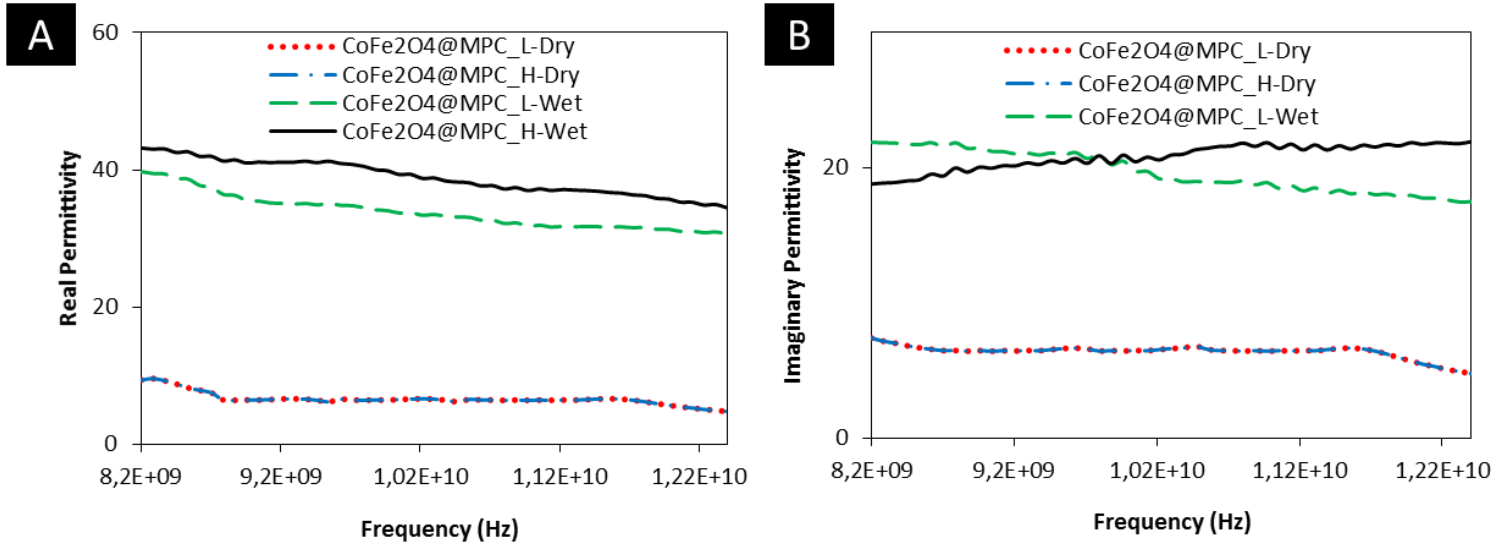

Figure S9. (A) Real permittivity and (B) imaginary permittivity for the magnetic NP loaded films with low and high loading over the $\mathrm{X}$-band frequency range. The results are presented for both dry and wet films. (The solid black line in B corresponds to CoFe2O4@MPC_HWet)

\section{References}

[1] Hamad, W. Y.; Hu, T. Q. Can. J. Chem. Eng. 2010, 88, 392-402.

[2] Rietveld, H. J. Appl. Crystallogr. 1969, 2, 65-71.

[3] Ruland, W. Acta Crystallogr. 1961, 14, 1180-1185. 